\title{
The Importance of Oocyte and Sperm Cryopreservation of Indonesian Genetic Resources of Local Sheep and Goat
}

\author{
Gatot Ciptadi ${ }^{1}$, Muh. Nur Ihsan ${ }^{1}$, Sri Rahayu ${ }^{2}$, and Mudawamah ${ }^{3}$ \\ ${ }^{I}$ Faculty of Animal Husbandry Brawijaya University, Malang, Indonesia. \\ ${ }^{2}$ Facultu of MIPA-Biology, Brawijaya University, Indonesia. \\ ${ }^{3}$ Faculty of Animal Husbandry, Islamic University of Malang.
}

\begin{abstract}
Animal breeding, genetic and reproduction are facing challenges with more powerful and useful methods for creating new breeds, genetic change and improvement. In the near future, the frozen cells of sperms and oocyte of local breed and animals have a potential to trade at a national, regional and international levels. These research goals were to study the oocyte and sperms cryopreservation of a specific breed, superior and potential of small ruminants for the the conservation of animal genetic resources for both research and commercial purposes. The study focused on the local breeds of goats and sheep breeds (PE and Senduro Goats) that have been selected genetically (chromosome and genetic DNA analysis). Sperm was produced and to be cryopreserved and storage in liquid nitrogen (-196 $\left.{ }^{\circ} \mathrm{C}\right)$. Variables observed are cell freezing and post-thawing quality as well as viability and live-dead $(\% \mathrm{t})$. Test fertility studies have been conducted in vitro testing of sperm quality. Meanwhile, oocytes were isolated from ovary obtained from locally slaughtered house, then matured in vitro and be frozen. The freezing oocytes were tested for their quality and fertility in vitro, base on IVF and cleavage rate (\%). The result showed that early genetic analysis has been completed and indicates that the Indonesia small ruminants (PE and Senduro) are categorized have a normal genetically base on chromosome analysis $((2 \mathrm{~N}=60, \mathrm{X}=$ acrosentris, $\mathrm{Y}=$ metasentris). Post-thawing quality of sperms is considered good quality with $\geq 40 \%$ motility (SNI 2008). From this research showed that both freezing sperm and oocyte method of Indonesia small ruminants is considered as good and potential as an alternative technology for conserving the valuable genetic materials. It was concluded that the cryopreservation of germ cells is an attractive and effective conservation the genetic resources of local, superior animal, rare as well as for endangered animals.
\end{abstract}

Keywords: Genetic, Frozen Sperm, Oocytes, Small Ruminant, Indonesia.

\section{INTRODUCTION}

Animal breeding, genetic and reproduction are facing challenges with more powerful and useful methods for creating new breeds, genetic change and improvement. The good breeding programs and better reproductive management completed with a recording by selection of superior animals, especially those that are used for frozen semen used in Artificial Insemination (AI) are very important. Application of AI in Indonesia is the main option to increase livestock production through the increase population and genetic quality. In the near future, the frozen cells of sperms and oocyte of local breed and animals have a potential to trade at a national, regional and international levels. These research goals were to study the oocyte and sperms cryopreservation of a specific breed, superior and potential of small ruminants for the conservation of animal genetic resources for both research and commercial purposes, especially for AI implementation.. 


\section{METHODS}

The study focused on the local breeds of goats and sheep breeds (PE and Senduro Goat) that have been selected genetically (chromosome and DNA analysis). Animal used for semen freezing was very high selected 4 heads from 249 heads (about 1,6\% rate selection). Sperm was produced and to be cryo-preserved and storage in liquid nitrogen $\left(-196{ }^{\circ} \mathrm{C}\right)$. Variables observed are cell freezing and post-thawing quality as well as viability and live-dead (\%t). Test fertility studies have been conducted in vitro testing of sperm quality. Meanwhile, oocytes were isolated from ovary obtained from locally slaughtered house, then matured in vitro. Briefly, ovaries were collected in bottles containing $0.9 \%$ sterile saline $(200 \mathrm{ml})$ added with penicillin 0.06 gram $/ 200 \mathrm{ml}$ and streptomycin $0.1 \mathrm{gram} / 200 \mathrm{ml}$ and were taken using a box with a $38^{\circ} \mathrm{C}$ of temperature. Aspiration of oocytes were performed on follicles with 3-6 mm of diameter using $10 \mathrm{ml}$ syringe with needle $18 \mathrm{G}$. Oocytes were chosen for culture is a good quality oocytes surrounded by more than 2 layers of cumulus cells and compact ( Ciptadi et al, 2016). The freezing oocytes were tested for their quality and fertility in vitro, base on IVF and cleavage rate (\%). Field testing of implementation of AI was done to observe the rate success of AI base on the Non Return Rate (NRR) or pregnancy rate (\%). For AI implementation test, 16 goats were synchronized and 15 normal females were selected to inseminate.

\section{RESULT AND DISCUSSION}

The result showed that early genetic analysis of goat used for semen freezing production has been completed and indicates that this Indonesia small ruminants (PE and Senduro goats) are categorized have a normal genetically base on chromosome analysis $((2 \mathrm{~N}=60, \mathrm{X}=$ acrocentric, $\mathrm{Y}=$ metacentric). It was recommended to screen breeding male animal for kariotypic abnormality, so that it cannot be transmitted to the next generation (Ahmad, et al, 2004).

Post-thawing quality of sperms is considered good quality with $\geq 40 \%$ motility (SNI 2008). The oocytes showed the variations of calsium intensity among activated M-II oocyte. Oocyte treated with CSE resulted in $36.33 \%$ cleavage rate $\left({ }^{1}\right)$.Figure 1 . Ciptadi et al (2016) reported that oocytes of local goat were dominated isolated from young female goat (pre-pubertal), but it's were competence to reach matured in vitro. From this research showed that both freezing sperm and oocyte method of Indonesia small ruminants is considered as good and potential as an alternative technology for conserving the valuable genetic materials. Field research of AI implementation resulted in about $80 \%$ success rate base on NRR and then pregnancy rate

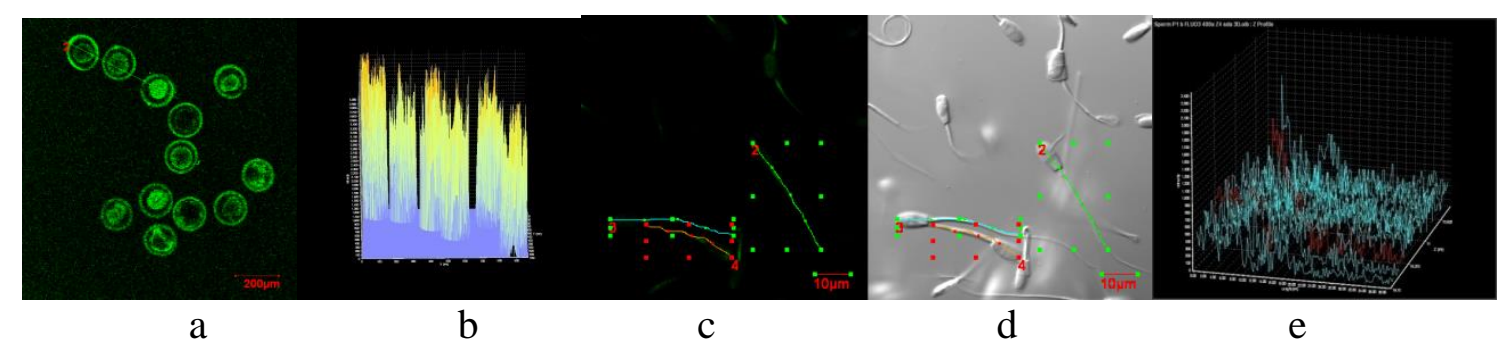

Figure 1: (a,b).Calcium intensity profile of oocyte and sperm of goat, expressed high spread out in cytoplasm.; (c,d,e). High variation of intensity respons on different sperms treated fresh and cryopreserved. Analysis was performed by CLSM-fluo 3.(Ciptadi, et al., 2012, 2016). 


\section{CONCLUSION}

It was concluded that the cryopreservation of germ cells is an attractive and effective conservation the local genetic resources of local, superior animal, rare as well as for endangered animals. Superior goat male for frozen semen production and AI need on guarantee of fertility, health and genetic quality.

\section{REFERENCES}

(1) Ciptadi, G, S. Rahayu and B.Siswanto. 2012. The phenotype Characters of Ca++ Intensity M-II Oocyte activated by Chemical and Crude Sperm Extract Stimulation. Proc. International Seminar WASET. Paris.

(2). Ciptadi1, G, S. Rahayu, Fatchiyah, Maidaswar, Sarastina, Nurhayati, S. Wahjuningsih, E. Herwiyanti ${ }^{3}$, Mudawamah and MN. Ihsan. 2016. The Oocyte and Sperms Cryopteservation of Local Small Ruminant for Conserving Genetic Material and Germs Cell Banking Realization. Proc. Internasional Seminar 3 rd APIS and 2 rd ARCAP, Batu Indonesia.

(3). Ahmad,I, K. Javed and A. Sattar. 2004. Screening of breeding bull of different breeds through karyotyping. Pakistas Veterinaire Journal 24 (4), 2004: 190-192.

(4) Ciptadi,G., Ali Harris, Helly Nurul Karima, and Setyawati. 2016. The Respond of Immature Oocytes from Prepubertal Indonesian Goat After Estrus Goat Serum (EGS) Supplementation On In-vitro Maturation Rate. Research Journal of Pharmaceutical, Biological and Chemical Sciences. September-October 2016 RJPBCS 7(5) Page No. 7-11. 